\title{
Sobre os limites da razão: um diálogo entre Lefort e Merleau-Ponty
}

About the Limits of Reason: a Dialog Between Lefort and Merleau-Ponty

\section{Alex de Campos Moura Universidade de São Paulo | São Paulo | Brasil}

\section{RESUMO}

Neste artigo procuramos fazer um breve comentário a respeito da leitura proposta por Lefort sobre o pensamento de Merleau-Ponty, buscando circunscrever e problematizar a forma pela qual ele reconhece no filósofo a manutenção tácita de um primado da razão, resquício de uma figura clássica do intelectualismo. Propomos discutir alguns dos eixos dessa interpretação, especialmente aqueles relacionados à compreensão merleau-pontyana sobre o corpo.

\section{PALAVRAS-CHAVE}

Lefort; Merleau-Ponty; Corpo; Expressão.

\begin{abstract}
In this article, we make a brief comment about the interpretation proposed by Lefort about Merleau-Ponty's thought, seeking to circumscribe and discuss the way he recognizes, in the philosopher, the maintenance of a primacy of reason, expression of a classic figure of intellectualism. We propose to discuss some of the axes of this interpretation, especially those related to Merleau-Ponty's understanding of the body.
\end{abstract}

\section{KEY WORDS}

Lefort; Merleau-Ponty; Body; Expression. 
Faremos um breve comentário a respeito da leitura proposta por Lefort sobre o pensamento de Merleau-Ponty. Nossa proposta principal é a tentativa de circunscrever e problematizar a forma pela qual ele reconhece no filósofo a manutenção tácita de um primado da razão, resquício de uma figura do intelectualismo da qual suas obras, sobretudo aquelas de seu período inicial, não teriam sido capazes de efetivamente desvincular-se.

Em um primeiro momento, procuraremos reconstruir, brevemente, sua leitura e as bases que a apoiam, buscando explicitar alguns dos elementos centrais que nos parecem implícitos em suas formulações. Em seguida, procuraremos propor um diálogo com essa interpretação, problematizando alguns de seus eixos, especialmente aqueles relacionados à compreensão merleau-pontyana sobre o corpo. Evidentemente, dada a amplitude e a relevância do diálogo entre os dois autores, faz-se necessário um recorte. Aqui nos concentraremos principalmente nos comentários feitos por Lefort em seus ensaios reunidos em Sur une colonne absent, especialmente os momentos referentes à sua descrição sobre a "ambiguidade" existente nas primeiras obras do filósofo.

Além disso, faz-se necessária, ainda, mais uma delimitação. Segundo nossa leitura, há dois eixos principais na leitura de Lefort, especialmente em sua vertente crítica: a noção de corpo e a noção de cogito. Dado o espaço de que aqui dispomos, será necessário optar pelo tratamento de um deles, no caso, o corpo. Elegemos, assim, esse eixo, para a investigação que desenvolveremos ao longo dessa apresentação. Cabe mencionar, contudo, que o outro eixo, referente à discussão a respeito do cogito, também se fará presente em nossas descrições, ainda que de modo indireto. Sobretudo, ele permanecerá no horizonte devido ao recurso que faremos à noção de expressão proposta por Merleau-Ponty, apoiando-nos nela como possibilidade de propor uma alternativa ao diagnóstico de Lefort de que haveria, nas primeiras obras do filósofo, uma completa ausência de mediação entre o transcendental e o irrefletido. Pretendemos mostrar, ao longo dessa exposição, que a noção de expressão impede conceber os termos de modo inteiramente distinto e desconexo, constituindo-se como uma mediação originária e pré-dual, o que significa reconhecer - como procuraremos sustentar - que ela traz implícita a exigência de uma outra noção de cogito e de pensamento. $\mathrm{O}$ tratamento detido e aprofundado desse aspecto, contudo, será feito por nós em um outro momento. Concentremo-nos, agora, então, na leitura de Lefort, seguindo como fio condutor suas formulações sobre o corpo e sobre sua relação com a reflexão.

No ensaio em questão, Lefort acompanha cuidadosamente o movimento presente nas primeiras obras de Merleau-Ponty, especialmente a Fenomenologia da Percepção e a Estrutura do Comportamento, a fim de explicitar nelas a presença de uma operação ambígua. Por um lado, caberia a elas inaugurar o estilo e a temática que caracteriza- 
riam todo o pensamento do filósofo, descritos por Lefort sobretudo pela presença de uma concepção própria de metafísica, intrinsecamente ligada ao corpo. Por outro, elas já estabeleceriam os limites e contradiçōes internas desse pensamento, tecendo os "nós" que obliterariam seu projeto mais geral. No núcleo dessas contradiçōes, como procuraremos mostrar, o que Lefort busca mostrar é a primazia de uma figura da racionalidade que se mantém, latente mas não rompida, enfraquecendo as descrições do filósofo e o alcance de suas proposiçôes. Vejamos esse movimento.

Concentrando-se na Fenomenologia da Percepção, Lefort inicia sua discussão mostrando que um dos eixos principais da obra estaria na articulação entre crítica à ideia de metafísica e "descoberta" da experiência do corpo (Lefort, 1978b, pp. I20, I2I). Esses dois elementos, defende ele, adquirem papel central no início da reflexão de Merleau-Ponty, sobretudo pela explicitação de sua correlação intrínseca: o debate com a metafísica envolve uma compreensão nova do corpo, enquanto arquétipo de um estatuto próprio do conhecimento, forma de reflexão singular. O "saber do corpo, dos olhos e das mãos" impede que se mantenha a concepção da consciência como puro saber de si. Antes de qualquer operação do juízo, ele traz a necessidade de um abandono da ideia de "afecção transcendental" em favor do reconhecimento dos "paradoxos da existência"; exige, assim, segundo Lefort, o deslocamento da concepção de transcendental, em favor do reconhecimento da existência como "arquétipo" do saber.

Não se trata, pondera ele, de uma substituição que daria ao corpo o lugar original que havia sido ocupado pela consciência ao longo do pensamento moderno. A Fenomenologia da Percepção se constitui também em torno de uma "reformulação do cogito, da liberdade e da temporalidade", isto é, ela não se esgota em um estudo sobre o corpo. . Como ele bem mostra, se a experiência pré-objetiva que é aí perseguida não pode ser encontrada sem relação com o corpo e com sua estrutura ${ }^{2}$, nem por isso ela se deixa reduzir a eles: não é possível localizar no corpo a gênese do mundo sensível e de sua representação; não se pode fazer dele o "originário", mas sim reconhecê-lo como seu meio privilegiado de acesso.

Essa não identificação entre "originário" e corpo não se deve apenas ao estatuto da corporeidade, mas principalmente - e esse ponto é central na leitura de Lefort - à maneira pela qual se compreende esse próprio originário: segundo ele, como "experiência muda" ou "vida irrefletida" da consciência (Lefort, 1978, p. II7).

I Talvez pudéssemos afirmar, nesse sentido, que a própria descrição do corpo não se esgota em si, envolvendo e sendo envolvida por essas descriçôes "simultâneas" referidas por Lefort.

2 Apenas como indicação, já que o tratamento dessa questão, aqui, ultrapassaria em muito o espaço de que dispomos, cabe lembrar que a noção de estrutura é central para o filósofo, presente ao longo de toda a sua obra, desde o início configurando-se como alternativa à dicotomia clássica instaurada entre sujeito e objeto. 
É ela o núcleo perseguido pelas descrições do filósofo, capaz, aparentemente, de colocar-se em um registro aquém dos marcos tradicionais do pensamento. $\mathrm{O}$ corpo assumiria centralidade, então, justamente por constituir-se como acesso privilegiado a esse solo visado pelo filósofo, "experiência do silêncio", de onde proviriam a fala e o saber — nessa apresentação, será, sobretudo, sobre essa compreensão que nos deteremos: a leitura do corpo como salvaguarda de uma experiência originária de silêncio, acesso a uma dimensão, por princípio, inexpressiva.

Vem daí, defende Lefort, seu privilégio no interior do projeto da fenomenologia merleau-pontyana: daquilo que ele denomina sua "função metafísica" e, sobretudo, de crítica à metafísica, reconhecendo-o como "objeto por princípio de sua denegação" (Ibid., p. I20). Nesse sentido, propõe ele, não se trata de uma crítica que desembocaria em simples negação, em ausência de saber, mas sim na exigência de uma nova configuração. Ele não atua como recusa da metafísica, mas como modo de recuperá-la em sua dimensão aberta e histórica, desdobrando-a em um outro horizonte possível. Assim, o "retorno aos fenômenos por meio do corpo" faria simultaneamente a crítica aos "prejuízos clássicos” e tornaria possível a explicitação daquilo que permanece latente por sob eles. É aí que se encontra, segundo Lefort, a força e a originalidade do projeto filosófico do autor. Não apenas propor uma reformulação da noção de metafísica como um dos eixos principais de sua filosofia, mas sobretudo configurá-la ao redor da explicitação de uma articulação intrínseca entre a descrição do corpo e a reformulação do estatuto do conhecimento.

Reconhecido esse horizonte mais amplo, é a partir dele que a leitura de Lefort passa propriamente a empreender seu movimento crítico, deslocando-se para a explicitação dos pontos em que esse projeto encontraria seus obstáculos principais. Segundo ele, é justamente aí, em seu delineamento geral, que o pensamento do filósofo já começaria a construir seus impasses, sobretudo pela escolha de seu eixo central: a tentativa de um retorno ao "originário", compreendido como experiência muda a ser absorvida pela "luz" da razão, implicando a proposta de uma identificação total entre o pensamento e a "vida irrefletida". Como veremos, esse é um dos aspectos mais importantes da leitura de Lefort, com o qual buscaremos dialogar mais diretamente: a compreensão de que o filósofo pretende, ainda que talvez de modo não inteiramente deliberado, estabelecer uma identidade entre o pré-reflexivo e a reflexão.

Nesse sentido, a questão que Lefort se coloca é compreender se, ainda que o corpo permita uma reformulação da metafísica, essa identidade não acabaria por inviabilizá-la ou, ao menos, restringir-lhe consideravelmente o alcance. Nos termos utilizados por ele, há um "risco" inerente ao projeto do filósofo: equipar a vida irrefletida ao pensamento, trazer à fala a experiência muda, não seria, uma 
vez mais, afirmar a homogeneidade e a soberania da razão? Não implicaria afirmar que toda experiência presta-se ao modelo de pensamento e que todo silêncio pode, em alguma medida, ser iluminado pela consciência?

Diagnóstico semelhante é feito por ele em relação a Estrutura do Comportamento, primeira obra do autor. É ali, segundo Lefort, que essa problemática, que se tornará central na Fenomenologia da Percepção, bem como suas contradiçõos de princípio, são formuladas pela primeira vez, estabelecendo o eixo que atravessará a obra do filósofo: nas palavras dele, o projeto de "pensar o impensável da metafísica: o corpo" (Lefort, 1978b, p. 147). É a Estrutura do Comportamento, pois, que circunscreve o campo em que o pensamento do autor se moverá, tanto em seu projeto explícito, quanto em suas tensões implícitas. Retomando o movimento operado em relação à Fenomenologia, Lefort reconhece, também aqui, uma ambiguidade de base: por um lado, a Estrutura estabelece o "norte" do projeto filosófico de Merleau-Ponty, circunscrevendo as questôes às quais seu pensamento não cessará de retornar; por outro, ela torna explícito, neste movimento mesmo, como o projeto já traz implícitas suas contradiçôes, configurando os limites e os impasses que acompanharão essa filosofia desde seu início.

Como ocorreria na obra posterior, aos olhos de Lefort, a Estrutura do Comportamento permaneceria profundamente tributária da tradição metafísica. Suas descrições não conseguiriam, de fato, desvincular-se das linhas de força que atravessam uma Tradição marcada pela hegemonia da subjetividade e pela afirmação de uma figura pura de transcendental: "sua interpretação das estruturas abre o caminho à crítica da representação e da expressão que ele desenvolverá posteriormente, mas ele não se liberta de uma concepção de transcendental que o ancora à filosofia da consciência” (Ibid., p. I48).

É aqui, segundo ele, que já se instaura toda a ambiguidade do projeto do filósofo, pois, ao mesmo tempo em que ele busca fazer da percepção um "evento" e voltar ao corpo como "abertura", ele reestabelece a unidade do mundo fenomenal por meio de "uma visão transcendental" (Ibid.). Todos os paradoxos, defende Lefort, se concentram na ideia de uma consciência transcendental que se encontra agora destituída de seus atributos, que não possui a lei de seu objeto, entretecida por uma abertura e por uma história (Ibid.). Ou seja, todos os paradoxos se concentrariam na tentativa de reformular a metafísica sem abrir mão da manutenção de uma figura "ambígua" de transcendental. Contradição que se atestaria em sua própria descrição: uma consciência destituída justamente daquilo que asseguraria sua transcendentalidade - paradoxo de base, que não deixaria de produzir outros. É como se o filósofo, em seu esforço para estabelecer um "campo novo de investigação", acabasse, por fim, não sendo capaz de sequer desvincular-se do que lhe fora legado pela Tradição, terminando por apenas reunir duas vertentes 
distintas, dispondo lado a lado concepções que, na verdade, permaneceriam incompatíveis. Mantida essa dualidade, a sobreposição dos campos não poderia "resolver-se" senão pela subsunção de um ao outro, implicando o predomínio de um polo sobre seu oposto, revelando-o, na verdade, como sua base e fundamento. É por essa razão que, ainda que aparentemente vinculado à história e ao corpo, o transcendental não seria destituído de sua centralidade e autonomia, mantendo-se como elemento soberano em qualquer relação.

São essas dificuldades nascidas na Estrutura do Comportamento que Lefort vê se desdobrarem na Fenomenologia da Percepção, como discutimos acima. A tentativa de igualar o ser ao pensamento, de absorver o irrefletido pela reflexão, seria a exacerbação dessa herança intelectualista que já as descrições sobre a estrutura teriam assumido, mesmo que de modo não inteiramente deliberado. Dessa forma, conclui ele, a reformulação pretendida pelo filósofo, ainda que pudesse implicar uma "saída do kantismo e do cartesianismo", não poderia significar, enfim, uma saída efetiva da metafísica (Lefort, 1978b, p. I2I), já que seu projeto, por princípio atado à manutenção de um transcendental hegemônico, a recolocaria sob a égide da tradição metafísica, ainda que à sua revelia.

É precisamente nesse ponto, no reconhecimento do núcleo ambíguo do pensamento de Merleau-Ponty, que o sentido da leitura do próprio Lefort se explicita:

Nosso propósito não sendo aqui senão o de investigar os limites de um projeto que, em seu princípio, tende a abrir uma passagem fora da tradição metafísica, nós devemos, injustamente, ignorar tudo aquilo que os transgride. Será suficiente então conduzir a questão até o ponto em que se desenvolve a contradição da Fenomenologia da Percepção - na qual retorna, sob um signo inverso, aquela que se encontrava denunciada em Descartes. (Ibid., p. I22).

Trata-se, pois, de averiguar a viabilidade de um projeto que se propõe como alternativa à metafísica clássica, buscando compreender em que medida sua pretensão se encontraria obstruída por princípio, refém da manutenção, ainda que tática, de premissas que não apenas a impediriam de realizar-se, mas, principalmente, de poder se realizar.

Assim, se há no ensaio dois momentos principais da crítica de Lefort, um que parte da Estrutura do Comportamento e outro que se escora na Fenomenologia da Percepção, o eixo que os conduz permanece o mesmo: explicitar esse "paradoxo" sobre o qual as primeiras obras de Merleau-Ponty gravitariam continuamente, evidenciando sua tentativa de escapar à metafísica, sobretudo pelo recurso a uma nova descrição do corpo, sem propor um abandono efetivo da compreensão clássica de transcendental. É nesse horizonte que a pretensão, por diversas vezes 
denunciada por Lefort, de identificar o irrefletido ao pensamento revela sua envergadura e seus riscos inerentes, implicando a possibilidade do retorno daquilo que o filósofo supunha afastado: por um lado, a "ficção" de uma coincidência entre o Ser e o pensamento e, por outro, a "ficção" de uma "linguagem antes da linguagem" (Ibid..), à qual a condução da experiência muda à sua expressão pura nos remeteria. A hegemonia da concepção clássica de razão se tornaria explícita na suposição de uma expressão plena e completa da experiência, garantida pela identidade entre o ser e o pensar - reposição, enfim, de um marco ao qual já o século XVII nos remetia, afastando profundamente o projeto do filósofo da pretensa superação do dualismo e de seus pressupostos.

Circunscrita, em linhas gerais, a leitura de Lefort, é precisamente sobre esse eixo de sua análise que nos ocuparemos aqui: a problematização da afirmação de que haveria, tacitamente, a possibilidade - e até mesmo a proposta - de uma identificação entre ser e pensamento nas primeiras obras de Merleau-Ponty. Para isso, como descrito no início, recorreremos principalmente à discussão sobre a noção de corpo, entendido por ele como "acesso ao silêncio originário", e à discussão sobre a noção de expressão ${ }^{3}$, averiguando se de fato é possível compreendê-las, como sua leitura parece propor, no interior de uma dinâmica dualista, cindida entre um campo inteiramente inexpressivo e um transcendental que viria iluminá-lo.

O primeiro ponto a discutir, então, é a possibilidade dessa afirmação de uma experiência inteiramente silenciosa, salvaguardada pelo corpo. Como tentativa de nos contrapormos a essa ideia, tomaremos como núcleo a discussão proposta pelo filósofo em A Fenomenologia da Percepção sobre a relação entre corpo e expressão, especialmente sua descrição do corpo como "potência expressiva".

Ao longo do livro, o corpo aparece, em diversos momentos e particularmente no capítulo O corpo como expressão e a fala, como "arquétipo" da dinâmica expressiva. Por expressão, defende ali o filósofo, não se deve compreender uma simples sobreposição de termos independentes, como se se tratasse da mera "junção" entre um signo e um significado inteiramente distintos, cada um uma entidade isolável, que apenas se articulariam extrinsecamente pelo movimento expressivo. Isto é, a expressão não deve ser compreendida como uma operação secundária e convencional de significação, que criaria uma relação dedesignação entre termos autônomos:

Para aquém dos meios de expressão convencionais, que manifestam meu pensamento ao outro porque, em mim como nele, já estão dadas significaçōes para cada signo, e que nesse sentido não realizam uma

3 A expressão é um tema central no pensamento de Merleau-Ponty. Aqui, nós a abordaremos de modo bastante circunscrito, conforme a problemática em questão. 
verdadeira comunicação, é preciso reconhecer, veremos, uma operação primordial de significação em que o expresso não existe separado da expressão e em que os próprios signos induzem seu sentido no exterior. É dessa maneira que o corpo exprime a existência total, não que ele seja seu acompanhamento exterior, mas porque a existência se realiza nele. (Merleau-Ponty, 1994, p. 229)

Exprimir, e essa é uma das ideias mais desenvolvidas ao longo da Fenomenologia da Percepção, não é constituir um signo que representaria uma significação, elemento indicativo que não manteria qualquer relação interna com o termo indicado. Ao contrário, a expressão, e essa é a originalidade da proposição do filósofo, significa fazer existir uma significação, dar-lhe estatuto existencial, realizá-la e constituí-la efetivamente. Em diversos momentos e por diversos caminhos, o autor busca desenvolver e sustentar essa compreensão: o signo e a significação não existem por si, não são realidades autônomas. O que existe é um movimento expressivo originário que desconhece a alternativa e a separação entre um e outro, constituindo, por uma mesma dinâmica, tanto o signo quanto a significação, não mais como elementos duais, mas como momentos de um processo único que se faz pelo trânsito entre imanência e transcendência. ${ }^{4}$

Nesse contexto mais amplo, um dos elementos centrais é o corpo, já que caberá a ele assegurar esse vir a ser de toda expressão e de todo expresso. Não é uma consciência abstrata quem instala os sentidos ao mundo, como se eles existissem previamente na imanência de uma interioridade que os desdobraria diante de si; ao contrário, é o corpo próprio, enquanto dinâmica de estruturação, quem os faz existir, tornando-os uma realidade no mundo. ${ }^{6}$ A expressão revela-se, então, como a operação por meio da qual o corpo faz uma significação existir ${ }^{7}$, instalando-a como uma dimensão ou como uma variação do mundo e de seu ser no mundo. Ele é o meio pelo qual o significado se faz existência, configurando-se efetivamente não apenas para o outro, mas também para si. $\mathrm{O}$ próprio do corpo, assim, não é manifestar algo que existiria previamente — que ele apenas "externaria” —,

4 Esses pontos são amplamente desenvolvidos pelo filósofo. Aqui propomos uma apresentação bastante circunscrita, tendo em visto o espaço de que dispomos e o tema geral que aqui nos ocupa.

5 A noção de expressão não se deixa descrever unicamente pelo corpo, envolvendo outros elementos correlacionados. Como descrito acima, fazemos aqui uma descrição circunscrita.

6 O mundo, bem entendido, não deve repor qualquer tipo de dualismo. Ele próprio é um campo relacional, pré-objetivo, cuja descrição é longamente desenvolvida pelo filósofo em A Fenomenologia da Percepção.

7 É importante lembrar que o próprio termo existência, em Merleau-Ponty, remete a uma articulação entre o empírico e o transcendental, como será amplamente discutido ao longo de toda a sua obra. 
mas sim "fazer ser", em seu sentido mais forte ${ }^{8}$, ao mesmo tempo como criação e consumação desse algo.

Mas nosso corpo não é apenas um espaço expressivo entre os demais. Este é apenas o corpo constituído. Ele é a origem de todos os outros, o próprio movimento de expressão, aquilo que projeta as significações no exterior, dando-lhes um lugar, aquilo que faz com que elas comecem a existir como coisas, sob nossas mãos, sob nossos olhos [...] é ele que dá à nossa vida a forma da generalidade e que prolonga nossos atos pessoais em disposições estáveis. (Merleau-Ponty, 1994, p. 63)

É como passagem do para-si ao em-si, como mediação originária, que o corpo opera. E é a partir desse reconhecimento que o filósofo poderá extrair inúmeros desdobramentos. ' Aqui, nos deteremos em apenas um deles, referente à reconfiguração dos termos aí implicados e, sobretudo, à explicitação de sua constituição relacional, mostrando a impossibilidade de se compreender a expressão como operante com termos exclusivos e autônomos, no interior de uma lógica dualista. Dinâmica encarregada de fazer a significação existir como uma estrutura aquém da cisão entre sujeito e objeto, ela não poderá submeter-se à lógica de um pensamento dicotômico.

Cabe, então, recorrermos a um exemplo bastante conhecido proposto pelo filósofo, em que essa dinâmica expressiva do corpo aparece de modo explícito, ajudando-nos a compreender precisamente o alcance e as implicações de suas descrições.

Ao discutir a dimensão de sexualidade própria à existência, Merleau-Ponty se reporta ao exemplo da afonia, particularmente ao caso de uma moça que perde a voz ao ser proibida de ver o rapaz que ama (Ibid., p. 22I). A questão, mostra ele, classicamente concebida, nos colocaria diante de duas possibilidades alternativas de compreensão. Na primeira, o sintoma seria uma espécie de deliberação do sujeito, a manifestação de uma decisão da consciência. Seria, então, necessário admitir que a moça decide recusar a "corrente da coexistência" e "absorver ou deglutir" a proibição e que, para exteriorizar essa recusa, ela decide perder a voz. Nesse caso, a afonia não seria senão uma espécie de signo escolhido pelo sujeito para representar sua decisão, uma significação já determinada e constituída, que apenas recorreria ao sintoma para trazer à exterioridade aquilo que a consciência já havia deliberado e conhecido de maneira completa: a perda da voz seria a

8 Conforme nossa hipótese de trabalho, em que defendemos a presença e a centralidade de uma dimensão ontológica desde as primeiras obras do autor. Conforme nossos trabalhos anteriores.

9 Esse aspecto, na verdade, constitui um eixo central de toda a Fenomenologia da Percep̧̧ão. 
manifestação externa de uma decisão e de uma significação inteiramente claras e distintas para si.

$\mathrm{Na}$ segunda opção, o sintoma seria algo que o sujeito padeceria - uma fatalidade advinda de condições objetivas - e, nesse caso, seria preciso admitir que não haveria qualquer escolha, que a paciente nada decidiria, e que a afonia, por fim, pouco teria a ver com a significação daquilo que se passava existencialmente com ela. Ela seria, então, o efeito de uma causalidade extrínseca, mecânica e objetiva, que operaria no sujeito sem manter com ele qualquer relação interna. Na primeira explicação, o sintoma seria o índice de uma "realidade" interior; no segundo, o índice de uma fatalidade mecanicamente configurada. Desaparece então, em ambos os casos, a relação de sentido entre o sintoma e a situação na qual figura; ele permanece algo externo, meramente designativo, produto ou efeito do que se passa no sujeito. Nas duas hipóteses, um signo exterior, sem qualquer significação intrínseca.

É essa dupla alternativa, mostra o filósofo, que torna impossível a compreensão do sintoma. Pois, na primeira hipótese, se ele não é senão a representação de uma significação que existiria por si e para si, não se poderia compreender como uma intervenção fisiológica poderia contribuir para seu desaparecimento. Em contrapartida, se ele fosse uma fatalidade objetiva, não se poderia compreender como ele se relaciona com o histórico do paciente e como o tratamento e o fim da proibição poderiam fazer com que a moça recuperasse a voz.

As duas hipóteses permanecem, pois, incapazes de compreender o sintoma tal qual a experiência nos dá testemunho dele. Em ambas, a "expressão" operada por ele é entendida como a configuração de uma relação meramente designativa, manifestação de algo distinto dela, seja uma ideia ou uma causalidade pura. Ela seria, enfim, o signo, inerte e vazio, que representaria algo que lhe seria inteiramente estranho.

Ao contrário, defende Merleau-Ponty, tornar-se afônico não é nem uma escolha e nem uma fatalidade, sendo justamente contra essas vertentes explicativas que a descrição do corpo como potência expressiva se coloca. Ao ser proibida de ver o rapaz que ama, a moça "perde" a voz assim como se "perde" uma recordação; não porque trate-se de uma perda objetiva - pois se ela fosse efetivamente posta pelo sujeito, não haveria de fato esquecimento ou perda (Merleau-Ponty, 1994, p. 223) —, mas porque o desaparecimento se dá aquém da dimensão objetiva e desconhece a alternativa entre a "escolha" e as "causas". Ao mesmo tempo em que não pode haver essa relação objetiva e posicional com o termo esquecido, sob pena de fazer do esquecimento uma dissimulação, é preciso, em contrapartida, que se estabeleça com ele uma relação intencional, isto é, o sintoma deve manter uma relação intrínseca e significativa com aquilo que é recusado, uma vez que é "aquele" campo em especial que é esquecido, não um campo qualquer ou um 
desaparecimento aleatório. Esquecer envolve uma negação do termo esquecido e, assim, alguma forma de conhecimento dele. Mas justamente por se tratar de uma recusa, é preciso que esse ato não seja explícito ou determinado, que não "coloque" seu termo de forma objetiva. O esquecimento, portanto, é um ato que não pode conhecer-se inteiramente, que se perde ao realizar-se: ação que se realiza justamente ao afastar-se de si, efetivando-se precisamente ao expressar-se.

Nesse sentido, cabe destacar, mesmo que de modo breve ${ }^{\mathrm{IO}}$, que essa descrição já traz também, implicitamente, uma problematização da noção de cogito ${ }^{\text {II }}$, pois a existência do sintoma segundo a dinâmica expressiva proposta pelo filósofo exige o reconhecimento de um sujeito que não tenha de si uma ideia clara e distinta e, ao mesmo tempo, que não se ignore. O esquecimento só é possível se há na subjetividade uma dimensão de distância ou de obscuridade, não como aquilo que a privaria de si, mas justamente como aquilo que lhe permite configurar uma relação de si a si, estabelecer consigo uma dinâmica intencional — sem a qual, por sua vez, também o esquecimento se tornaria impossível, já que uma subjetividade que não fosse, em alguma medida, "saber de si”, "relacionar-se a si”, não poderia efetivamente esquecer, recusar uma região vital específica, já que todas lhe seriam igualmente indiferentes. Trazendo à tona a tensão sobre a qual a compreensão do cogito deverá constituir-se, é nesse campo híbrido entre o saber de si e o ignorar-se que ele deverá se situar - o que, por si só, parece tornar difícil sustentar a ideia de que ele seria apenas a reposição de uma figura do transcendental tal qual concebido pela Tradição. ${ }^{\text {I2 }}$

Retornando ao eixo de nossa argumentação, o importante aqui é compreender que, ao afirmar que a paciente perde a voz do mesmo modo como se perde uma lembrança, o propósito do filósofo, recuperando o caminho de sua descrição, é mostrar que a expressão não pode ser compreendida como a manifestação secundária de uma significação que, por princípio, existiria para si e por si, liberta de toda relação e de toda aparição, alojada na pura imanência do sujeito. Exprimir não é um movimento tardio inscrito em uma lógica dual.

Outro exemplo particularmente esclarecedor dessa dinâmica é dado pelo filósofo em relação à cólera. Ao procurar descrever o sentido dos gestos corporais, o filósofo se coloca diante de uma questão similar: qual o sentido do gesto da cólera e, sobretudo, de que modo ele se articula à significação aí em curso. No

Io Como descrito no início, não poderemos, nessa apresentação, nos dedicar ao tratamento aprofundado dessa questão.

II Apenas como indicação, cabe lembrar que esse é um tema central no interior da Fenomenologia da Percepção e bastante controverso entre os estudiosos de Merleau-Ponty.

I2 Como descrito no início, aqui apenas tateamos a questão. Ela abre um horizonte amplo, do qual não poderemos nos ocupar aqui. 
momento em que o corpo expressa a cólera, ele estaria recorrendo a um signo para manifestar um sentido que existiria por si, na imanência da subjetividade, ou ele estaria manifestando o resultado de uma causalidade objetiva, um processo mecânico do qual a cólera não seria senão o efeito necessário? Em ambos os casos, curiosamente, o gesto colérico nada diria por si, afirmando-se apenas como índice ou designação de algo diverso. Razão pela qual, defende o filósofo, nenhuma das hipóteses consegue efetivamente compreendê-lo, uma vez que o fenômeno principal que ele realiza não é a designação de uma significação exterior, mas precisamente sua encarnação ou sua realização. O gesto colérico é a própria cólera, no momento em que ela se faz realidade para si e para outrem. A expressão do gesto é a existência do sentido, significação que vem ao mundo, estruturando-se como campo e situação.

Ela não é, portanto, a indicação de um estado emocional, o signo de uma consciência insular ou o resultado de uma vida interior, mas sim a efetividade de uma dinâmica unitária que desconhece a cisão entre significado e existência, entre signo e sentido. ${ }^{13}$

Esses exemplos, ainda que bastante breves, nos permitem, enfim, circunscrever o aspecto central que gostaríamos de discutir aqui, como forma de problematizar algumas das proposiçóes de Lefort: a dinâmica expressiva, em Merleau-Ponty, não pode ser compreendida como uma operação polarizada entre dois termos inteiramente distintos, um "silêncio absoluto" e uma expressividade absoluta. Ela não reata com a lógica dual segundo à qual seria necessário optar entre a completa exterioridade e a completa identidade dos termos, repondo o transcendental e irrefletido em seu sentido clássico. Ao contrário, a expressão, compreendida a partir da lógica do corpo e do decorrente reconhecimento da inseparabilidade entre a expressão e o expresso, exige a afirmação de uma articulação mais originária, aquém da alternativa entre um e outro. ${ }^{14}$ Como vimos, se o corpo é a encarnação mesma da significação, sua realização e existência, mais do que "guardião" de uma experiência inexpressiva, ele pode ser compreendido, segundo nossa hipótese brevemente circunscrita aqui, como uma mediação originária, configuração em que o signo e o sentido coexistem indissoluvelmente, longe do dualismo e de suas relações de recíproca exclusão.

I3 A expressão reencontra assim uma temática central em toda a obra do autor, a busca por um campo híbrido que desconheça a cisão entre os termos que a Tradição concebeu de forma opositiva e exclusiva.

I4 Cabe lembrar que esse tema, central ao longo de todo o pensamento de Merleau-Ponty - e, como procuramos mostrar brevemente aqui, também já em suas primeiras obras -, será retomado com especial ênfase em suas discussões sobre Cézanne e em seus estudos sobre a linguagem, explicitamente comprometidos com a proposta de compreender a maneira pela qual se entretecem, na linguagem, seus "fios de silêncio". Conforme, por exemplo, A Prosa do Mundo e Signos. 
Assim, é possível propor, a partir dessa formulação mais geral, que seria difícil afirmar propriamente a existência de um "antes" da expressão, um solo inteiramente inexpressivo, cujo sentido último seria trazido à luz por meio de um puro transcendental. O que nos parece mais próximo das descriçōes do filósofo é a constatação da existência de uma dinâmica originária, vinculada à corporeidade, aquém da dicotomia dos termos, encarregada precisamente de configurá-los, ensinando seu caráter estruturalmente relacional e processual. Se por expressão o filósofo compreende o processo de "fazer ser", "fazer existir" um sentido, não nos parece possível entendê-la, como defende Lefort, como "acesso a uma experiência silenciosa”, mas sim como a própria efetivação de uma experiência que, por princípio, furta-se a todo silêncio completo.

\section{Referências}

Lefort, Claude (1978a). Les Formes de l'histoire, Paris: Gallimard.

Lefort, Claude (1978b). Sur une colonne absente. Écrits autour de Merleau-Ponty, Paris: Gallimard.

Lefort, Claude (198I). L'Invention démocratique. Les Limites de la domination totalitaire, Paris: Fayard.

Merleau-Ponty, Maurice (1964). Le Visible et le Invisible, Paris: Gallimard.

Merleau-Ponty, Maurice (1967). La Structure du Comportement, Paris: Puf.

Merleau-Ponty, Maurice (1969). La Prose du Monde, Paris: Gallimard.

Merleau-Ponty, Maurice (1994). Fenomenologia da Percepção, trad. Carlos Alberto Ribeiro de Moura, São Paulo: Martins Fontes.

Merleau-Ponty, Maurice (2003). Signes, Paris: Gallimard. 